\title{
Report of the presence of Phlebotomus (Phlebotomus) salehi Mesghali in Sri Lanka: a potential cutaneous leishmaniasis vector
}

\author{
K. Gajapathy* and S.N. Surendran \\ Department of Zoology, Faculty of Science, University of Jaffna, Jaffna.
}

\begin{abstract}
Cutaneous leishmaniasis (CL) is emerging as a serious public health threat in Sri Lanka and more than 2000 cases have been reported during the past nine years. The parasite responsible for CL has been identified as Leishmania donovani zymodeme MON -37. Phlebotomus (Phlebotomus) salehi is a proven vector of oriental sore or CL in India. Phlebotomus (Euphlebotomus) argentipes sensu lato, which is a vector of $L$. donovani that causes visceral leishmaniasis (VL) in India, is suspected to be a vector of CL in Sri Lanka. But the vector of CL in Sri lanka is yet to be determined. Cattle- baited collection and hand picking techniques were used for sandfly collection in three CL endemic localities, namely, Vavuniya, Anuradhapura and Trincomalee. Female Ph. (Phl.) salehi flies from the collections were identified based on morphological and published morphometric characters. This is the first record of the presence of $P h$. (Phl.) salehi in the country.
\end{abstract}

Keywords: Leishmaniasis, Phlebotomus (Phlebotomus) salehi, sandfly, Sri Lanka, vector.

\section{INTRODUCTION}

Leishmaniasis is a global health threat affecting 88 countries in tropical and warm temperate regions (Ilango, 2011). Sandflies (Diptera: Psychodidae: Phlebotominae) are the vectors of leishmaniasis and the taxonomy of the sandflies are being updated regularly. In recent time, new species have been reported and the taxonomy of previously reported taxa has been reassessed. Among the 700 species of sandflies reported so far in the world, more than 30 are proven to be the vectors for leishmaniasis (Ilango, 2011).

Leishmaniasis is a major public health concern in Sri Lanka since the first report of the autochthonous case of cutaneous leishmaniasis (CL) in 1992 (Athukorale et al., 1992). Since then the number of cases has been increased dramatically. More than 2000 cases have been reported from the country in the last nine years (Siriwardana et al., 2010). The first case of visceral leishmaniasis (VL) was identified from the North Central Province of the country in 2006 (Abeygunasekara et al., 2007).

Leishmania donovani zymodeme MON -37 was identified as the causative agent for CL in Sri Lanka (Karunaweera et al., 2003). The vector for the disease however, is yet to be confirmed apart from a recent study showing the vectorial capacity of Phlebotomus (Euphlebotomus) argentipes sensu lato (Senanayake et al., 2011). This species harbours a closely related strain of $L$. donovani, which causes VL in India. This is the proven vector for VL in many parts of India including the Southern State of India (Ilango, 2011), which lies in close proximity to Sri Lanka. In addition to this vector, other species such as Phlebotomus papatasi Scopoli and $P h$. salehi Mesghali are proven vectors of CL or oriental sore in India, which is caused by L. major.

As leishmaniasis is emerging as a major public health threat in Sri Lanka (Navaratna et al., 2007), proper identification of the sandfly vector species is of paramount importance. With this background, a survey was carried out at some CL prevailing localities in Sri Lanka to record the presence of any potential CL vectors.

\section{METHODS AND MATERIALS}

Phlebotomine sandflies were collected using cattlebaited collection $(\mathrm{CBC})$ and hand picking techniques. Samplings were done using a mouth aspirator from 
$1800-0600 \mathrm{~h}$, during the period of May 2010 to February 2011 at different sites in three districts, namely, Vavuniya (Chettikulam, Pambaimadu, Maniarkulam villages), Trincomalee (Nilaveli, Padavi Siripura) and Anuradhapura (Padaviya, Anuradhapura) Districts located in the Dry Zone of Sri Lanka (Figure 1). Two samplings were done in each site in the Trincomalee District and five samplings each from the sites in the other districts. Baits were setup in selected locations (with accessibility and convenience in setting up the bait) after monitoring for the presence of sandfly.

Sandflies were preserved using conventional techniques (Lewis, 1978; Ko et al., 2008). Microscopic analysis was done with Kyowa Model SE- L (Japan), Olympus Model BX 51 (Japan) and a monocular light microscope (Kyowa, Japan) equipped with a moving vernier scale and an ocular micrometer. Photographs of the taxonomic features were taken with a Nikon Coolpix Digital Camera (10 megapixels).

Morphometric and meristic characters were analysed and identification of species was done with the published taxonomic keys (Lewis, 1978; Kakarsulemankhel, 2003; Lane, 1993). Morphological features were compared with the existing literature from the South-East Asian region (Kakarsulemankhel, 2003) (Table1).

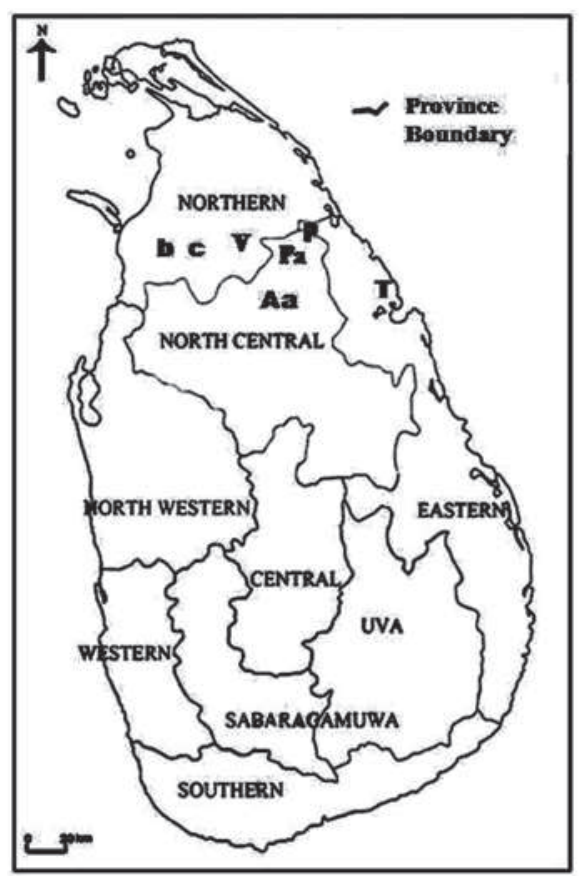

Figure 1: Sample collection sites (letters $\mathrm{A}, \mathrm{T}$ and $\mathrm{V}$ denote districts of Anuradhapura, Trincomalee and Vavuniya, respectively and letters $\mathrm{Pa}, \mathrm{P}, \mathrm{a}, \mathrm{b}$ and $\mathrm{c}$ denote collection sites Padavi Siripura, Padaviya, Anuradhapura, Maniarkulam and Chettikulam, respectively)

Table 1: Comparison of the morphological characters used in the identification of female Phlebotomus (Phlebotomus) salehi Mesghali (all measurements are in $\mu \mathrm{m}$ )

\begin{tabular}{lll}
\hline Character & $\begin{array}{l}\text { Kakarsulemankhel (2003) } \\
\text { in Pakistan }\end{array}$ & Present study in Sri Lanka \\
\hline Wing length & $1600-1680$ & $1700-1750$ \\
Wing breadth & $464-544$ & 480 \\
Wing index $\left(\mathrm{R}_{2} / \mathrm{R}_{2+3}\right)$ & $1.56-1.6$ & 1.875 \\
AIII length & $180-210$ & 180 \\
AIII/Labrum & 1.0 & 0.86 \\
AIII/AIV+AV & AIII $<=$ AIV + AV & 1.17 AIII $>$ AIV+AV \\
Labrum length & $260-300$ & $210-216$ \\
AaIV/AIV & 0.459 & 0.7 \\
Cibarium & $5-6$ small denticles scattered & Scattered 6 small denticles on \\
& and few lateral teeth & anterior without pigment patch \\
Pharynx & $2.61-2.64$ & 3.0 \\
length/breadth & & \\
Spermatheca & Conical , 7-8 segmented with & 8 segments with large last segment \\
& larger last segment, narrow & and tip with projections. Ducts are \\
ducts all over the place & large and narrow. Chitinous furca \\
& & is present \\
\hline
\end{tabular}




\section{RESULTS}

Only 02 female $P h$. (Phl.) salehi Mesghali flies were found in the collection in Maniarkulam village in Vavuniya along with Phlebotomus (Euphlebotomus) argentipes Annandale and Brunette species complex (Gajapathy et al., 2011) and 14 species belong to Sergentomyia Franca and Parrot (Table 2) (Gajapathy \& Surendran, 2011a,b). Phlebotomus Rondani \& Berte was distinguished, based on the absence of prominent cibarial teeth and pigment patch and the presence of erect hairs in hind abdominal sockets. They were distinguished as subgenus Phlebotomus Rondani \& Berte by the presence of ridges and scales in the pharyngeal armature and equally thick spermathecal segments (especially the last spermathecal segment) (Lewis, 1978; Lane, 1993; Kakarsulemankhel, 2003). Taxonomic characters such as the relative length of third antennal segment (AIII) compared with that of labrum $(\times 0.8)$ and $\mathrm{AIV}+\mathrm{V}$ $(>\times 1.0)$; presence of small denticles in cibarium; number

Table 2: The list of identified sandfly species during 2010-11 from the districts of Anuradhapura, Vavuniya, Trincomalee and Jaffna

\begin{tabular}{|c|c|c|}
\hline Genus & Subgenus & Species \\
\hline Phlebotomus & Euphlebotomus & argentipes Annandalae \\
\hline Phlebotomus & Euphlebotomus & annandalei Sinton $\ddagger$ \\
\hline Phlebotomus & Euphlebotomus & glaucus Mitra \& Roy \\
\hline Phlebotomus & Phlebotomus & salehi Mesghali \\
\hline Sergentomyia & Parrotomyia & barraudi Sinton $¥$ \\
\hline Sergentomyia & Parrotomyia & babu insularis Theodor, \\
\hline Sergentomyia & Parrotomyia & rudnicki Lewis $¥$ \\
\hline Sergentomyia & Parrotomyia & baghdadis Adler \& Theodor \\
\hline Sergentomyia & Parrotomyia & $\begin{array}{l}\text { species A Kaul, Dhanda \& } \\
\text { Modi } ¥\end{array}$ \\
\hline Sergentomyia & Parrotomyia & modii Lewis $¥$ \\
\hline Sergentomyia & Parrotomyia & grekovi Khodukin $¥$ \\
\hline Sergentomyia & Parrotomyia & bailyi Sinton $¥$ \\
\hline Sergentomyia & Sergentomyia & punjabiensis Sinton \pm \\
\hline Sergentomyia & Sergentomyia & $\begin{array}{l}\text { pondicherriensis Srinivasan } \\
\& \text { Jambulingam } \pm\end{array}$ \\
\hline Sergentomyia & Sergentomyia & dentata Sinton \pm \\
\hline Sergentomyia & Grassomyia & $\begin{array}{l}\text { dreyfussi turkestanica } \\
\text { Theodor \& Mesghali } ¥\end{array}$ \\
\hline Sergentomyia & Grassomyia & indica Theodor $¥$ \\
\hline Sergentomyia & Neophlebotomus & malayae Lewis $¥$ \\
\hline
\end{tabular}

\$ Gajapathy et al., 2011

$¥$ Gajapathy and Surendran, 2011b

\pm Gajapathy and Surendran, 2011a of spermathecal segments (7-8) with broader anterior segment, were used in the identification of $P h$. (Phl.) salehi Mesghali (Kakarsulemankhel, 2003).

The morphological features of the identified $P h$. (Phl.) salehi Mesghali flies were as follows: thorax + abdomen length 1830-1850 $\mu \mathrm{m}$; thorax + abdomen breadth 260-265 $\mu \mathrm{m}$; head length 380-390 $\mu \mathrm{m}$; head breadth 340-350 $\mu \mathrm{m}$; eye length $210 \mu \mathrm{m}$; eye breadth $140 \mu \mathrm{m}$; eye separation $90 \mu \mathrm{m}$; wing length $1700-1750 \mu \mathrm{m}$; wing breadth $480 \mu \mathrm{m}$; halter length $17 \mu \mathrm{m}$.

Fore femur: fore tibia: fore basi tarsi 6.5:19:15; mid femur: mid tibia: mid basi tarsi 7:19:16; hind femur: hind tibia: hind basi tarsi 8:18:20.

Mouth parts: The labrum is a chitinized pointed structure with three apical sensilla. The hypopharynx is with marginal teeth and the mandible is with serrated teeth at the edge. Maxillary blade has visible teeth with 22 ventral and 11 laterals. Cibarium is with small denticles scattered from without a pigment patch. Pharynx is broader at base, with network like ridges and scales at the anterior. Pharynx is three times its breadth.

Labrum length $210-216 \mu \mathrm{m}$; maxillary palp length $4200 \mu \mathrm{m}$; palp formula $(1,4,2,3,5)$ with a ratio of 3:9:14:5.5:10.5; proboscis length $220 \mu \mathrm{m}$; third antennal segment (AIII) $180 \mu \mathrm{m}$; AIV $78 \mu \mathrm{m}$; AV $76 \mu \mathrm{m}$; antennal ascoid/ sensilla chaetica on third antennal segment (AaIII) $50 \mu \mathrm{m}$; AaIV $54 \mu \mathrm{m}$; AaV $52 \mu \mathrm{m}$.

Wing venation: First radial vein (R1) $690-700 \mu \mathrm{m}$; R2 450-456 $\mu \mathrm{m}$; R3 560-580 $\mu \mathrm{m}$; R 2+3 $240 \mu \mathrm{m}$; R1 overlap $24 \mu \mathrm{m}$.

Genitalia: Segmented spermatheca has 8 segments. The last segment is broader and with a small projection. The individual ducts are fused to form a common duct and then lead into the genital atrium. Chitinous furca present. Spermatheca length is $30-32 \mu \mathrm{m}$; breadth is $16 \mu \mathrm{m}$ at the broadest part.

\section{DISCUSSION AND CONCLUSION}

This is the first report of the presence of Phlebotomus (Phlebotomus) salehi Mesghali from Sri Lanka, a species in the subgenus Phlebotomus. The other two species reported in the subgenus, $P h$. (Phl.) papatasi Scopoli and $P h$. (Phl.) bergeroti Parrot have not been reported from Sri Lanka. The flies were collected from Maniarkulam village of Vavuniya District, which is considered as an area with the risk of CL (Siriwardana et al., 2010). 


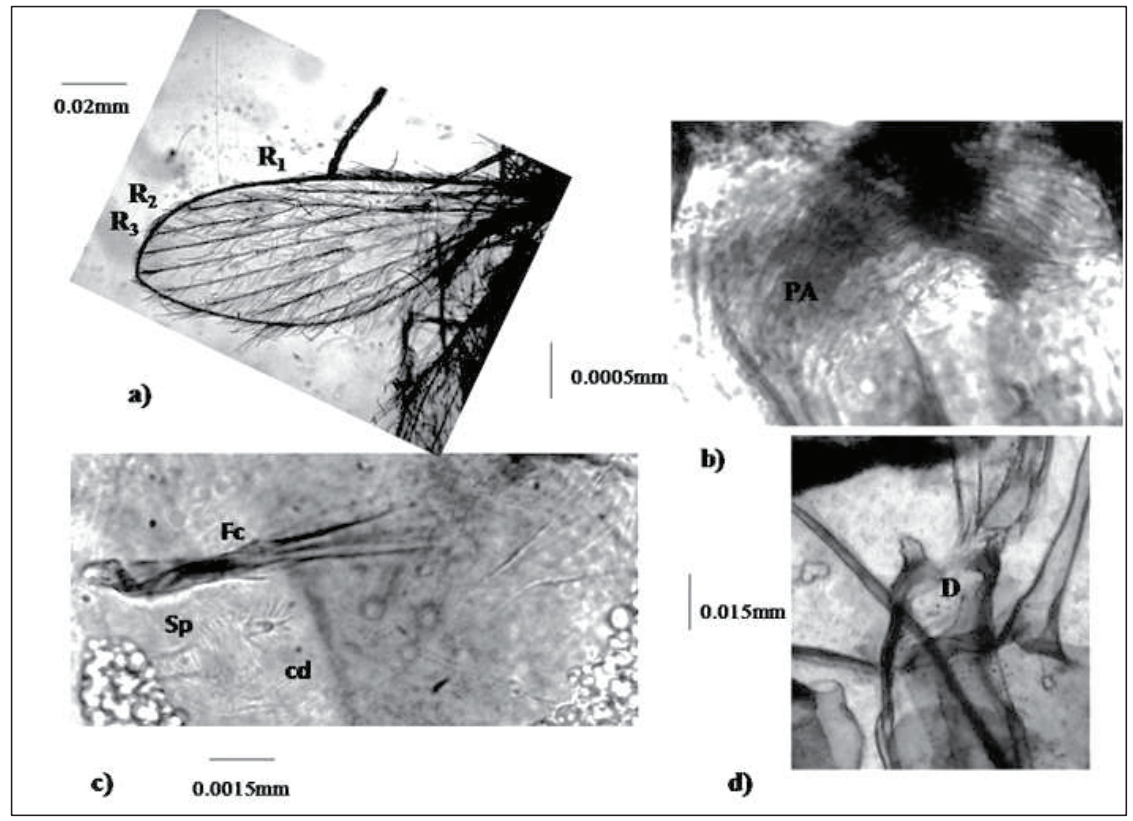

Figure 2: Images of female Phlebotomus (Phlebotomus) salehi Mesghali. a) Wing showing radial $\left(\mathrm{R}_{1}, \mathrm{R}_{2}\right.$ and $\mathrm{R}_{3}$ ) veins; b) pharyngeal armature (PA); c) spermatheca ( $\left.\mathrm{Sp}\right)$, furca (Fc) and common duct (cd); d) cibarium and denticles in scatter (D)

The morphology of the Sri Lankan flies is similar to that of the flies in Pakistan, described by Kakarsulemankhel (2003), except for some minor deviations. The flies in Sri Lanka have comparatively larger AIII and higher wing index (R2/R 2+3) values. The antennal ascoid (sensilla chaetica) of the AIV is also comparatively larger.

The presence of Ph. (Phl.) salehi Mesghali in Sri Lanka especially in CL prevailing locality, necessitates a detailed analysis on the species richness and diversity of sandflies and their role in leishmaniasis transmission in the country. Presence of more than one insect vector species for a pathogen is a well established concept in epidemiology. Adetailed entomological survey along with vector incrimination is warranted to establish the epidemiology of leishmaniasis in Sri Lanka.

\section{Acknowledgement}

The study received financial assistance from the National Research Council of Sri Lanka (NRC/6/24) and the University Grants Commission of Sri Lanka. The approval from the Department of Wildlife Conservation of Sri Lanka for conducting the study is also acknowledged.

\section{REFERENCES}

1. Abeygunasekara P.H.Y., Costa J., Seneviratne N., Ratnatunga N. \& Wijesundera S.M. de (2007). Locally acquired visceral leishmaniasis in Sri Lanka. Ceylon Medical Journal 52(1): $30-31$.

2. Annandale N. (1908). Notes on oriental Diptera. V. Description of a new species of psychodid of the genus Phlebotomus. Records of Indian Museum 2(1): 101-104.

3. Athukorale D.N., Seneviratne J.K.K., Ihalamulla R.L. \& Premaratne U.N. (1992). Locally acquired cutaneous leishmaniasis in Sri Lanka. Journal of Tropical Medicine and Hygiene 95(6): $432-433$.

4. Gajapathy K., Jude P.J. \& Surendran S.N. (2011). Morphometric and meristic characterization of Phlebotomus argentipes species complex in northern Sri Lanka: evidence for the presence of potential leishmaniasis vectors in the country. Tropical Biomedicine 28(2):259 -268.

5. Gajapathy K. \& Surendran S.N. (2011a). Morphometric description of sandflies belong to genus Sergentomyia (Sergentomyia) (Diptera; Psychodidae; Phlebotominae) in Sri Lanka; evidence for the presence of Sergentomyia (Sergentomyia) pondicherriensis \& Sergentomyia (Sergentomyia) dentata in the country. Journal of Entomology 8(6):512 - 529.

6. Gajapathy K. \& Surendran S.N. (2011b). Sandfly (Diptera: 
Psychodidae: Phlebotominae) diversity in Sri Lanka; special reference to some leishmaniasis endemic localities. 5th Conference of Medical Arthropodology (eds. B.K. Tyagi, T. Mariappan, P. Philip Samuel, V. Thenmozhi, A. Venkatesh, V. Rajamannar \& E. Raja), Madurai, India, 18-19 October, Centre for Research in Medical Entomology, India, p. 13.

7. Ilango K. (2011). Spatial and temporal distribution of Phlebotomine sandflies in relation to Leishmaniasis in India. Entomology (Ecology \& Biodiversity) (eds. B.K. Tyagi \& Veer Vijay), pp. 99 -103. Scientific Publishers, India.

8. Kakarsulemankhel J.K. (2003). Sandfly (Diptera: Psychodidae: Phlebotominae) fauna of South-Western Pakistan.1. diagnosis morphology of Phlebotomus papatasi (Scopoli), Ph. bergheroti (Parrot) and Ph. salehi (Mesghali). Parasitologia 45(2): 103-118.

9. Karunaweera N.D., Pratlong F., Siriwardena H.V.Y.D., Ihalamulla R.L. \& Dedet J.P. (2003). Sri Lankan cutaneous leishmaniasis is caused by Leishmania donovani zymodeme MON-37. Transactions of the Royal Society of Tropical Medicine and Hygiene 97(4): 380-381.

10. Ko H.Y., Wang H.S., Huang J.J., Lu L.C. \& Chen C.H. (2008). Sandfly Distribution and Risks of Leishmaniasis Transmission in Kinmen. Taiwan Epidemiology Bulletin
24(48): $269-278$.

11. Lane R.P. (1993). Sandflies (Phlebotominae). Medical Insects and Arachnids, pp. 92 - 96. Chapman and Hall, London, UK.

12. Lewis D.J. (1978). The phlebotomine sandflies (Diptera, Psychodidae) of the oriental region. Bulletin of British Museum Natural History (Entomology) 37(2): 217-343.

13. Mesghali A. (1965). Phlebotominae (Diptera) of Iran III. studies on sandflies in the area of Bander Abbas and Jask. Bulletin of the Exotic Pathology Society 58(2): 259 - 276.

14. Navaratna S.S.K., Weligama D.J., Wijekoon C.J., Dissanayake M. \& Rajapaksha K. (2007). Cutaneous leishmaniasis, Sri Lanka. Journal of Emerging Infectious Diseases 13(7): 1068 -1070.

15. Senanayake S.A.S.C., Abeyewickreme W., Abeysinghe R.R., Dotson E. \& Karunaweera N. (2011). Phlebotomus argentipes: possible vector of leishmaniasis in Sri Lanka, Annual Research Symposium, University of Colombo, Sri Lanka, 28 June 2011., University of Colombo, Sri Lanka, OP1.

16. Siriwardana H.V.Y.D., Thalagala N. \& Karunaweera N.D. (2010). Clinical and epidemiological studies on the cutaneous leishmaniasis caused by Leishmania (Leishmania) donovani in Sri Lanka. Annals of Tropical Medicine and Parasitology 104(3): 213 -223. 